\title{
Primary Care in Rheumatoid Arthritis
}

\author{
Nahid Kianmehr ${ }^{1}$, Ali Afrasiabi ${ }^{1}$, Shabnoor Abdullatif ${ }^{1}$, Hamed Ansari ${ }^{2}$, Fatemeh Shirani ${ }^{1}$, Ali Sobhani \\ firoozabadi ${ }^{1}$, Anousheh Haghighi ${ }^{1 *}$ \\ ${ }^{1}$ Department of Internal Medicine, Hazrat Rasool-e-Akram Hospital, Iran University of Medical Sciences and Health \\ Services, Tehran, Iran. ${ }^{2}$ The college of Family Physicians of Canada.
}

General practitioners (GPs) play an important role in the early diagnosis, treatment, and referral of rheumatoid arthritis (RA) patients. Many patients do not receive rheumatologist care at the appropriate time. Therefore, it seems necessary to evaluate the knowledge and attitude of GPs toward RA to identify some of the barriers in the optimal care of patients with RA delivered by GPs. A total of 120 GPs were selected through simple and non-random sampling from physicians participating in five educational seminars held in Tehran. The survey used in this study questioned their experience with RA, with prescribing disease-modifying anti-rheumatic drugs (DMARDs), and with making referrals to a rheumatologist.

Among the GPs in this study, 28.3\% had no RA patients monthly, 35.8\% declared that they visit 3-5 RA patients per month on average, and95 out of 120 (79.2\%) referred RA patients to a rheumatologist as soon as possible. The majority of physicians (87.5\%) sourced their knowledge about rheumatoid arthritis mostly from their general medical training. $47.5 \%$ had low and $5 \%$ lacked self-esteem in managing RA patients. $92.5 \%$ of GPs were familiar with DMARDs, but only $22.1 \%$ of them had ordered them. Lacking knowledge about the side effects of DMARDs was the main reason for hesitance in prescribing them. The results also revealed that older, male, and more experienced GPs were more comfortable in managing RA patients.

This study showed that the RA care delivered by GPs is not consistent with current treatment guidelines focusing on early DMARDs therapy. GPs do not have enough information or confidence for managing patients with RA. Improving physicians' knowledge and continued educational programs are suggested.

Keywords: Rheumatoid arthritis, knowledge, General practitioners, perspective

\section{Introduction}

Rheumatoid arthritis (RA) is the most prevalent inflammatory disease of the joints [1]. Risk factors are age (risk increases with age; most patients are in their 60s), a positive family history, smoking, obesity, recent infection, and being of the female gender $[1,2]$. One study suggested that the early diagnosis and treatment of RA are necessary to prevent joint deformity, save function, and recover quality of life [3]. Early intervention, i.e. within 12 weeks of onset of the illness, could minimize the adverse sequelae of RA and optimize long-term prognoses [4-5]. Disease-modifying antirheumatic drugs (DMARDs) are the first line medications for managing RA. Other treatments include nonsteroidal anti-inflammatory drugs (NSAIDs), glucocorticoids, nutritional supplements, exercise, physiotherapy, and joint replacement surgery [6-10]. Studies show that patients with RA who are referred to a rheumatologist have a 31-times greater chance of receiving DMARDs than patients seen by other physicians [11, 12]. Moreover, at least two studies revealed that patients under the supervision of a rheumatologist have better results, although most RA patients do not recourse to rheumatologists. Only 34\% of the patients in this study were visited by a rheumatologist over a 2-year period $[12,13,14]$.

General practitioners are the first and sometimes only physicians that patients consult. Therefore, the first management of these patients depends on the doctor knowing the new guidelines and treatment protocols for RA [13, 15]. Despite considering RA in differential diagnoses, many GPs prefer to introduce their patients to rheumatologists; $25 \%$ do not. Moreover, it is rare for a GP to begin treatment with DMARDs $[16,17]$. GPs play a fundamental role in monitoring patients who take DMARDs prescribed by a rheumatologist. Even so, there is little information about how such doctors manage early RA, their attitude and self-confidence in prescribing DMARDs, or about referral plans to rheumatologists [18-22]. The aim of the current study was to survey the knowledge and attitude of GPs regarding the management of RA patients and to understand the obstacles they face in caring for them.

Personal non-commercial use only.Rheumatology Research Journal. Copyright (C) 2019. All rights reserved

*Corresponding Author: Anousheh Haghighi, Department of Internal Medicine, Hazrat Rasool-e-Akram Hospital, Iran University of Medical Sciences and Health Services, Tehran, Iran. Email: haghighi533@yahoo.com, Tel/Fax: (+98)021-66509145,64352451

Received: 25 April 2020; Accepted: 01 July 2020 


\section{Materials and Methods}

Participant selection was accomplished through five seminars for general practitioners as continuous medical education (CME) in Tehran, Iran. These physicians were supposedly representative of general practitioners as they had moved to Tehran (the capital of Iran) from different parts of the country. Through this easy and non-randomized sampling, questionnaires were distributed to 120 GPs who worked as family medicine doctors, general practitioners, or emergency physicians. During a systematic review in related research, Dr. Rudeman's questionnaire comprising 25 questions for rheumatologists, internal medicine physicians, and general practitioners was identified [23]. Because the target of this study was GPs, 12 questions were first selected, translated into Persian, and confirmed by five rheumatologists who were attending physicians in Iran's University of Medical Sciences. The questionnaire was validated based on the content validity score index. The results showed convenient validity: comprehensiveness $=0.82$, relevancy $=$ 0.82 , clarity $=0.85$. The reliability of this questionnaire in Farsi was applicable, and Cronbach's alpha was 0.78 . The questionnaire include demographic information and RA-related questions. The RA-related questions focused on the doctors' experience with patient treatment, prescribing DMARDs, and patient referral (Table 1). Mean and standard deviation values were used for quantitative variables such as age and hours of work, and percentages were used for qualitative variables such as workplace and gender. Comparisons between quantitative variables were performed by t-test in normal and the Mann-Whitney $\mathrm{U}$ test in non-normal distributions. To compare between qualitative variables, the Chi-Square and Fisher exact tests were used, and data was analyzed using SPSS version 20. A p-value less than 0.05 was considered significant. Correlates of prescribing DMARDs were examined in logistic regression models.

Table 1. Question included in questionnaire

1. What is your weakly working time?
3. How many RA patients do you visit every month?
4. $\quad$ In what condition do you refer RA patients to rheumatologist?
5. How many percent of RA patients do you refer?
7. $\quad$ How is your knowledge references about RA?
8. Do you know DMARDs (Disease Modifying AntiRheumatic Drugs)?
9. Do you have any experience with DMARDs?
10. When is the proper time to start DMARDs?
11. What is the cause of DMARDs non-prescription?
12. What is your recommendation to make RA care better?

\section{Results}

Questionnaires were distributed in five national congresses as part of the continuous medical educational program (CME), in which 550 GPs, 136 physicians agreed to participate in this survey, and $120(21.8 \%)$ of them properly and fully completed the questionnaire (Figure 1).

Among the participants, $41.7 \%$ were men and 58.3\% were women. Other demographic characteristics are given in Table 2. The majority of physicians had practiced for less than 10 years $(81.7 \%)$. Physicians had worked in various places, like clinics $(41.7 \%)$, hospitals $(47.5 \%)$, and private offices $(10.8 \%)$. Almost $53.3 \%$ of the physicians referred RA patients as soon as possible after diagnosis and $13.3 \%$ made referrals after one month of treatment; $20.8 \%$ of physicians, however, stated that they had never introduced an RA patient to a specialist. The results further showed that male GPs and older GPs are more inclined to refer RA patients to rheumatologists than young female GPs. 


\begin{tabular}{|l|}
\hline Total accessible sample $=550 \longrightarrow$ did not participate $=414$ \\
Accepted questionnaire $=136 \longrightarrow$ did not fill $=16$ \\
Completed survey $=120$
\end{tabular}

Figure 1. Description of sampling assemble

Table 2. Characteristics of survey participants $(n=120)$

\begin{tabular}{|c|c|}
\hline VARIABLE & VALUE \\
\hline $\begin{array}{l}\text { Age average(years) } \\
\text { Frequency of gender }\end{array}$ & $33.78 \pm 7.52$ \\
\hline Male no. $(\%)$ & $50(41.7 \%)$ \\
\hline Female no. $(\%)$ & $70(58.3 \%)$ \\
\hline \multicolumn{2}{|l|}{ Medical experience } \\
\hline$<10$ years & $98(81.7 \%)$ \\
\hline $11-15$ years & $9(7.5 \%)$ \\
\hline$>15$ years & $13(10.8 \%)$ \\
\hline \multicolumn{2}{|l|}{ Workplace } \\
\hline Teaching hospital & $28(23.3 \%)$ \\
\hline community hospital & $29(24.2 \%)$ \\
\hline Clinics & $50(41.7 \%)$ \\
\hline Private office & $13(10.8 \%)$ \\
\hline \multicolumn{2}{|c|}{ Number of working hours per week } \\
\hline$<20$ hours & $34(28.3 \%)$ \\
\hline $20-40$ hours & $43(35.8 \%)$ \\
\hline$>40$ hours & $43(35.8 \%)$ \\
\hline
\end{tabular}

The rate of referral to a rheumatologist was higher among GPs with more years of experience. Male practitioners refer patients to specialists within 1 month, but females refer those with advanced disease within 3 months. Older male GPs who had worked more hours and visited more patients per day reported having more confidence in managing RA patients. Male practitioners preferred to start treatment with DMARDs after diagnosis, but females preferred to wait 6 months after diagnosis or after trying NSAIDs and glucocorticoids. The main sources of knowledge for older practitioners were undergraduate education $(87.5 \%)$ and self-education through textbooks or articles (5\%), while younger physicians preferred to attend CME programs and seminars $(7.5 \%)$.

The average confidence rate was $47.5 \%$, while optimal confidence was $32.5 \%$. Over half of the GPs mentioned 
initiating DMARDs right after diagnosis of RA; however, nearly one third of GPs stated that DMARDs should be ordered after non-steroidal anti-inflammatory drugs (NSAIDs) and glucocorticoids had been tried (Table 3). Younger, less experienced GPs mostly believed that increasing the awareness and knowledge of patients and GPs is the best way to improve RA patient's outcome, while older more experienced GPs recommended more available Rheumatism Care for patients.

Among the participant GPs, those who had worked in community hospitals were least knowledgeable.

Lack of competency and medication side effects were GPs' main reasons for hesitating to prescribe DMARDs.

Table 3. Information on RA patient's management and DMARDs* prescribing

\begin{tabular}{|c|c|}
\hline VARIABLE & VALUE \\
\hline \multicolumn{2}{|l|}{ Number of visits per month } \\
\hline 0 & $4(28.3 \%)$ \\
\hline $1-2$ & $43(35.8 \%)$ \\
\hline $3-5$ & $43(35.8 \%)$ \\
\hline \multicolumn{2}{|l|}{ Referral time to rheumatologist } \\
\hline Immediately after the diagnosis & $64(53.3 \%)$ \\
\hline No response to treatment in 1 month & $16(13.3 \%)$ \\
\hline No response to treatment in 3 month & $13(10.8 \%)$ \\
\hline Advanced disease & $15(12.5 \%)$ \\
\hline Never & $12(10 \%)$ \\
\hline \multicolumn{2}{|l|}{ Frequency distribution of referrals } \\
\hline$<10 \%$ & $19(15.8 \%)$ \\
\hline $10-50 \%$ & $15(12.5 \%)$ \\
\hline$>50 \%$ & $86(71.7 \%)$ \\
\hline \multicolumn{2}{|l|}{ Source of physician knowledge } \\
\hline Medical school & $105(87.5 \%)$ \\
\hline Medical congress and continuous educational programs & $9(7.5 \%)$ \\
\hline Journals & $6(5 \%)$ \\
\hline \multicolumn{2}{|l|}{ Self-confidence } \\
\hline Perfect & $18(15 \%)$ \\
\hline Good & $39(32.5 \%)$ \\
\hline Low & $57(47.5 \%)$ \\
\hline Lack of confidence & $6(5 \%)$ \\
\hline Familiarity with DMARDs & $111(92.5 \%)$ \\
\hline Experience treatment with DMARDs & $29(22.5 \%)$ \\
\hline
\end{tabular}




\begin{tabular}{cc}
\hline VARIABLE & VALUE \\
\hline Time to start DMARDs & $64(53.3 \%)$ \\
Immediately after diagnosis & $9(7.5 \%)$ \\
6 months & $47(39.2 \%)$ \\
If glucocorticoids and NSAIDs are not effective & \\
The reason for not prescribing the DMARDs & $55(45.8 \%)$ \\
Fear of Infection & $6(5 \%)$ \\
Lack of sufficient knowledge & $55(45.8 \%)$ \\
Uncertainty about diagnosis & $4(3.3 \%)$ \\
\hline
\end{tabular}

*Disease-modifying anti-rheumatic drug; RA, rheumatoid arthritis.

\section{Discussion}

The current study evaluated the knowledge and perspective of GPs as the primary and main care providers on the management and referral of RA patients to rheumatologists. Most GPs visited less than five RA patients in a month. This represents that Iranian practitioners are not sufficiently updated about the management of RA patients. Approximately $20 \%$ of GPs had no exposure to RA patients. This could be the result of a lack of diagnosis of RA or the easy availability of a specialist in some areas.

Most Iranian patients prefer to be visited by a specialist right away. Patients for whom early intervention with DMARDs therapy is introduced by a specialist have better function and outcomes than those for whom such treatment is deferred. As many times GPs are the first and only managing physicians, this finding is not a good one. The absence of proper science in detecting symptoms early, fears of side effects, and low self-confidence in starting DMARDs lead to treatment delays and may have detrimental effects on disease remission and long-term outcome.

A literature review for articles regarding the prescription of DMARDs and physicians' attitudes to RA patients turned up several points. Stack et al. found that general practitioners should know more about RA in order to differentiate the early signs and symptoms of RA from those of other diseases [24]. Garneau et al. highlighted that low confidence and a lack of accessibility to rheumatologists were the main problems in prescribing DMARDs. Compared with Garneau's survey, the current study had fewer practitioners who participated in CMEs about RA. Moreover, there was less experience with the use of DMARDs. This result might be because of the inclusion of specialists in their study. Similar to the current survey, few studies reported that most practitioners avoided the use of DMARDs by themselves, and $80 \%$ of them preferred to introduce RA patients to specialists as soon as possible [12, 16, 19, 25]. Despite Glazier's study, [17] the current study found that male GPs suggested a referral of their patient more often than females, although the knowledge and confidence levels of men were higher than those of females. In the current study, factors such as high age, gender, workplace, and hours of work affected the perspective and management of patients among practitioners. It was also found that older GPs with more hours of work experience were more confident in the management of RA patients. This could be the result of a greater shortage of specialists in previous years, which made GPs more engaged in RA management.

The limitations of this study were the non-randomized sampling of participant GPs and data gathering through the use of a questionnaire instead of through interviews.

\section{Conclusion}

This study shows that Iranian GPs are not well-informed or confident in managing RA patients; however, it is noteworthy that most GPs suggested referring RA patients to rheumatologists. Sometimes, rheumatologists are not accessible, and the early diagnosis and intervention with DMARDs improves patient outcome; therefore, RA diagnosis and management and prompt referral to the rheumatology department should be specifically emphasized in CME programs and medical school education.

\section{Acknowledgments}

The authors would like to thank all those who helped them writing this paper.

\section{Conflict of Interest}

The authors declare no conflicts of interest. 


\section{References}

1. Symmons DP. Epidemiology of rheumatoid arthritis: determinants of onset, persistence and outcome. Best Pract Res Clin Rheumatol 2002; 16(5):707-22. doi: 10.1053/ berh.2002.0257.

2. Scott DL, Wolfe F, Huizinga TW. Rheumatoid arthritis. Lancet 2010; 376(9746):1094-1108. doi: 10.1016/S01406736(10)60826-4.

3. Smolen JS, Landewé R, Breedveld FC, Buch M, Nurmester $\mathrm{G}$, Dougedos $\mathrm{M}$, et al. EULAR recommendations for the management of rheumatoid arthritis with synthetic and biological disease-modifying anti-rheumatic drugs: 2013 update. Ann Rheum Dis 2014; 73(3):492-09. doi: 10.1136/annrheumdis-2013-204573.

4. van der Linden MP, le Cessie S, Raza K, van der Woude D, Knevel R, Huizinga TW et al. Long-term impact of delay in assessment of patients with early arthritis. Arthritis Rheum 2010; 62(12):3537-46. doi: 10.1002/art.27692.

5. Bosello S, Fedele AL, Peluso G, Gremese E, Tolusso B, Ferraccioli G. Very early rheumatoid arthritis is the major predictor of major outcomes: Clinical ACR remission and radiographic non-progression. Ann Rheum Dis 2011; 70(7):1292-95. doi: 10.1136/ard.2010.142729.

6. Kelly RB. Acupuncture for pain. Am Fam Physician 2009; 80(5):481-84.

7. Han A, Robinson V, Judd M, Taixiang W, Wells G, Tugwell P. Tai chi for treating rheumatoid arthritis. Cochrane Database Syst Rev 2004;(3):CD004849. doi: 10.1002/14651858.CD004849.

8. Evans S, Cousins L, Tsao JC, Subramanian S, Sternlieb $\mathrm{B}$, Zeltzer KL. A randomized controlled trial examining Iyengar yoga for young adults with rheumatoid arthritis. Trials 2011; 12:19. doi: 10.1186/1745-6215-12-19.

9. Katchamart W, Johnson S, Lin HJ, Phumethum V, Salliot $\mathrm{C}$, Bombardier C. Predictors for remission in rheumatoid arthritis patients: a systematic review. Arthritis Care Res (Hoboken) 2010; 62(8):1128-43. doi: 10.1002/acr.20188.

10. Baecklund E, Iliadou A, Askling J, Ekbom A, Backlin C, Granath F, et al. Association of chronic inflammation, not its treatment, with increased lymphoma risk in rheumatoid arthritis. Arthritis Rheum 2006; 54(3):692-01. doi: 10.1002/art.21675.

11. Schmajuk G, Schneeweiss S, Katz JN, Weinblatt ME, Setoguchi S, Avorn J, et al. Treatment of older adult patients diagnosed with rheumatoid arthritis: improved but not optimal. Arthritis Rheum 2007; 57(6):928-934. doi: 10.1002/art.22890

12. Lacaille D, Anis AH, Guh DP, Esdaile JM. Gaps in care for rheumatoid arthritis: a population study. Arthritis Rheum 2005; 53(2):241-48. doi: 10.1002/art.21077.

13. Shipton D, Glazier RH, Guan J, Badley EM. Effects of use of specialty services on disease-modifying antirheumatic drug use in the treatment of rheumatoid arthritis in an insured elderly population. Med Care 2004; 42(9):907-13. doi: 10.1097/01.mlr.0000135810.39691.f6.
14. Yelin EH, Such CL, Criswell LA, Epstein WV. Outcomes for persons with rheumatoid arthritis with a rheumatologist versus a non-rheumatologist as the main physician for this condition. Med Care 1998; 36(4):513-22. doi: 10.1097/00005650-199804000-00007.

15. Foley KA, Denke MA, Kamal-Bahl S, Simpson R Jr, Berra K, Sajjan S, et al. The impact of physician attitudes and beliefs on treatment decisions: lipid therapy in high-risk patients. Med Care 2006; 44(5):421-28. doi: 10.1097/01. mlr.0000208017.18278.1a.

16. Bernatsky S, Feldman D, Shrier I, Toupin K, Haggerty J, Tousignant $\mathrm{P}$, et al. Care pathways in early rheumatoid arthritis. Can Fam Physician 2006; 52(11):1444-45.

17. Glazier RH, Dalby DM, Badley EM, Hawker GA, Bell MJ, Buchbinder R, et al. Management of the early and late presentations of rheumatoid arthritis: a survey of Ontario primary care practitioners. CMAJ 1996; 155(6):679-87.

18. Pollard LC, Graves H, Scott DL, Kingsley GH, Lempp H. Perceived barriers to integrated care in rheumatoid arthritis: Views of recipients and providers of care in an inner-city setting. BMC Musculoskelet Disord 2011; 12:19. doi: 10.1186/1471-2474-12-19.

19. Rat AC, Henegariu V, Boissier MC. Do primary care physicians have a place in the management of rheumatoid arthritis? Joint Bone Spine 2004; 71(3):190-97. doi: 10.1016/j.jbspin.2003.09.003.

20. Suter LG, Fraenkel L, Holmboe ES. What factors account for referral delays for patients with suspected rheumatoid arthritis? Arthritis Rheum 2006; 55(2):300-05. doi: 10.1002/art.21855.

21. Laires PA, Mesquita R, Veloso L, Martins AP, Cernadas R, Fonseca JE. Patient's access to healthcare and treatment in rheumatoid arthritis: The views of stakeholders in Portugal. BMC Musculoskelet Disord 2013; 14:279. doi: 10.1186/1471-2474-14-279.

22. Stross JK, Bole GG. Continuing education in rheumatoid arthritis for the primary care physician. Arthritis Rheum 1979; 22(7):787-91. doi: 10.1002/art.1780220717.

23. Ruderman,Eric M. "An Assessment of Current Clinical Practices in Rheumatoid Arthritis CME". Questionnaire. 19 March 2015.

24. Stack R, Llewellyn Z, Deighton C, Kiely P, Mallen C, Raza K. General practitioners' perspectives on campaigns to promote rapid help-seeking behaviour at the onset of rheumatoid arthritis. Scand J Prim Health Care 2014; 32(1):37-43. doi: 10.3109/02813432.2014.900239.

25. Garneau KL, Iversen MD, Tsao H, Solomon DH. Primary care physicians' perspectives towards managing rheumatoid arthritis: room for improvement. Arthritis Res Ther 2011; 13(6):R189. doi: 10.1186/ar3517. 